\title{
Investigation of Voltage Sag and Swell Problems using DVR and Fuzzy Logic
}

\author{
Abhijith Augustine \\ Research Scholar \\ PRIST University \\ Thanjavur, India
}

\author{
Ruban Deva Prakash, \\ Ph.D \\ Principal \\ HEERA Engineering College \\ Thiruvanathapuram, India
}

\author{
Rajy Xavier \\ Assistant Professor \\ METS School of Engineering \\ Thrissur, India
}

\begin{abstract}
The term power quality becomes one of the touching concepts in present day economy. Due to its increased concern in the emerging industries, the importance of delivering true power is of a key issue. The concept of true power mainly depends on how correctly the issues like voltage sag and voltage swell are mitigated. Among all the power quality problems, the above mentioned are of key importance. This is because of the extensive use of newly invented as well as the outdated sensitive equipments connected to the load. Sensitivity is the main cause of the above power quality problems and it cannot be eliminated completely as it has many other operating properties. So the next possible solution is to correct the problems caused by the sensitive equipments connected to the faulty loads. The occurrence of sag and swell varies with equipment, environment, process operations, desired control schemes etc. by referring IEEE standards, the power quality events will last only for small instants. Thus the real time detection becomes a really tough task and even a small instant variation will cause a series of problems to the process industry. The dynamic voltage restorer is a special type of power device used for providing consistent and reliable supply power to the load devices. Dynamic voltage restorer uses a vector control strategy for mitigating power quality problems by automatically detecting and injecting the voltage components through an injection transformer. Repeated occurrence of sag and swell will cause these equipments to malfunction. Here comes the importance of soft computing techniques like fuzzy logic. With the help of a newly developed fuzzy rule base, the system will be able to correct repeated occurrences of the power quality problems.
\end{abstract}

\section{Keywords}

Voltage Sag, Voltage Swell, Dynamic Voltage Restorer, Power Quality, Fuzzy Logic Controller

\section{INTRODUCTION}

A voltage sag is regarded as a sudden decrease in the rms voltage $^{[1,2]}$ whereas a voltage swell is regarded as a sudden increase in the rms voltage; which is usually caused by a remote fault located somewhere on the equipment or control system. Voltage sags are major causes of the problem which the major process equipments are facing. The various equipments like process controllers, PLC's ${ }^{[3]}$ adjustable speed drives etc. are more sensitive to these power quality problems. These devices are more complex and sophisticated as they are working on advanced algorithms ${ }^{[4]}$. The complexity of these devices cannot be avoided, as it is closely related to the design process. There are numerous internal factors which affect a good power source. The only possible solution is to mitigate the sag and swell events using certain algorithms ${ }^{[7,8]}$ and also to reduce the chance of occurrences of these events. By our observation, it is seen that less sensitive equipments like relays, motors etc. are also affected by the power quality problems. Regular occurrences will damage the equipment and will result in an imbalance in reactive power and they will also lead to the shutdown of the whole process. The real time mitigation of sag and swell becomes important because of an objective; ie, to satisfy the customer side as well as the vendor side. This is regarded as the main economic impact of power quality. The lack of true power will make the economy weaken.

While considering the economic impacts, the major concern is towards the increased interest in the power quality, ${ }^{[5]}$ and increase in efficiency. Many survey results have proved that the impact of sag and swell ${ }^{[10]}$ have resulted in losing in terms of thousands of dollars in the total economic outcome. The best choice in selecting a suitable algorithm and a non linear device depends on the cost of the problem and also the total operating cost of the process, and generally it is a tough task to estimate the correct value. There are various technologies for improving power quality. They are evaluated in terms of cost, economic efficiency, the expected performance and improvements employed. The performance improvements will normally translate to economic benefits which are generally point towards the total power quality improvements.

Voltage sag analysis ${ }^{[5,6,9]}$ is a systematic and periodic analysis of collecting data which can be used to evaluate the network's performance. The characterization of sag events is a complex task and also the duration of the event existence, because these events will change their character with respect to time. The cost factor will also matter. Thus the correct detection will be very important. In normal test conditions, the sags will last to some seconds and a $10 \%$ decrease in the level of supply voltage (IEEE 1159) and it means that necessary reactive power is not being transferred to the load. The faults are the main cause for sag occurrence and the faults can happen anywhere in the plant (plant feeder breaker) or in the utility system (substation breaker). The major faults occur in a utility system, maybe of single line to ground fault (SLGF); three phase faults are also seen, but not in common. The SLGF will be caused by the factors like type of conductor, animal contacts, accidents, atmospheric variations, etc. and cannot be eliminated completely. In the test system described here, I am designing a three phase fault, which is easier to analyze than the single phase fault. From the customer side, faults (and, therefore, voltage sags) are inevitable, and therefore it is important to make sure that critical equipment sensitive to voltage sags is adequately protected.

Voltage swell is generally regarded as the opposite of voltage sag and is defined as the short increase in rms voltage (IEEE 1159), and is mainly caused by a short circuit or overloading of motors. As per standards, the swell happens for a period of 0.5 cycles to a minute, and if the swell lasts for more time, it is called as sustained swell. The disturbance is also described by IEEE C62.41-1991 as "A momentary increase in the power-frequency voltage delivered by the mains, outside of 
the normal tolerances, with duration of more than one cycle and less than a few seconds". Swells also have the same economic impact on power quality and are equally important as sag. The effects of sag are more noticeable and frequent. The effects of a voltage swell are often more destructive. It may cause breakdown/shutdown of components on the power supplies of the equipment.

These power quality problems can be alleviated by cooperation of the utility, end-user and the equipment manufacturer in order to reduce the number and frequency of occurrence to reduce the sensitivity of equipment. Distributed generation is a conventional method for electrical power generation in the present industry and is referred to as an electrical power source connected to the distribution system directly. But the power quality impacts will vary from device to device and nature of the customers. With Matlab's GUI, it is possible to simulate the two mentioned power quality events, and can be used for the purpose of further analysis purposes.

\section{OPERATION OF DYNAMIC VOLTAGE RESTORER}

Dynamic Voltage Restorer (DVR) is a device ${ }^{[11,12]}$ used to produce a sustainable and reliable power to the sensitive electrical equipment during the occurrence of power quality problems, DVR is mainly used to detect and mitigate voltage sag and swell. The DVR is different from conventional voltage regulators ${ }^{[13]}$ with no voltage source. The DVR uses an additional energy source, which is used to boost the energy levels during the dip occurrences, and this is interconnected to an energizing transformer. But this energy source is limited. Thus this mitigation technique will be successful only for short term happenings. But the DVR is found very effective in improving the transient responses and harmonic compensation, finally reducing the total harmonic distortion. Normally a DVR is connected in series to the supply after the fault happening. The DVR can provide a maximum of $50 \%$ compensation ${ }^{[14,15]}$ to the distorted supply level and this is based on active power supplied by the energy devices. The main feature of DVR includes its reliability, lower cost, smaller size, fast response to faults etc. The DVR has an inbuilt capacity to control the active power flow inside the component. In normal operating conditions, the DVR stands in the stand-by mode and will be active only if a disturbance occurs. In the injection point, the amplitude and phase angle of the injected voltages are different and variable, depending on the type and duration of the problem occurrence.

\subsection{Operating Modes}

The operation of a DVR is characterized in three modes normally regarded as protection mode, standby mode and boost mode. The boost mode of operation is selected during the occurrence of sag. Here the DVR injects the compensating voltages to the line supply through injection transformers. In the protection mode of operation of the DVR, it is used for short circuiting of the connected load and is achieved by isolating the DVR from load; while in the standby mode, the device acts as a standby protection device, and is achieved by shorting the low voltage side of the booster transformer. Figure 1 shows the schematic arrangement of the operating modes of DVR.

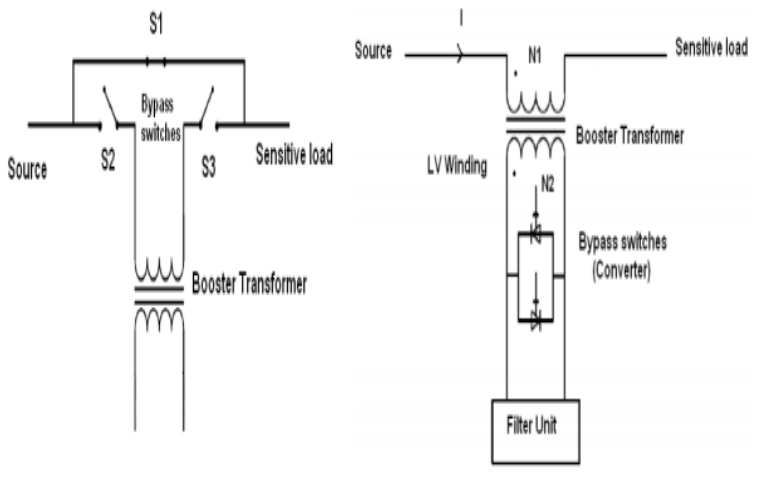

Fig 1 (a)Protection mode of DVR, (b)Standby mode of DVR

\subsection{Transformer Voltage Injection Techniques}

The voltage injection is achieved with the help of an injection transformer through an energy storage device by means of forced commutated converter. A voltage source inverter is also provided to control the three phase operation of the injection transformer. The role of injection transformers will be a vital one as it is used in ensuring maximum efficiency and reliability and thereby increasing the effectiveness of the connected scheme. The inverter gives the injection voltage; before it is filtered so as to eliminate the harmonics. Normally the injection transformer is connected in parallel through a bypass switch. The injected voltage and the supply voltage will be in the same phase so as to avoid phase overlapping. The special design flexibility of DVR provides a greater switching accuracy to the pulse width modulation (PWM) control methodology. The PWM will generate sinusoidal signals with the help of comparing a saw tooth wave and sending signals to the inverter. An LC filter is also added to rectify the harmonic components presented in the injected voltage. The system block diagram is shown in figure 2 .

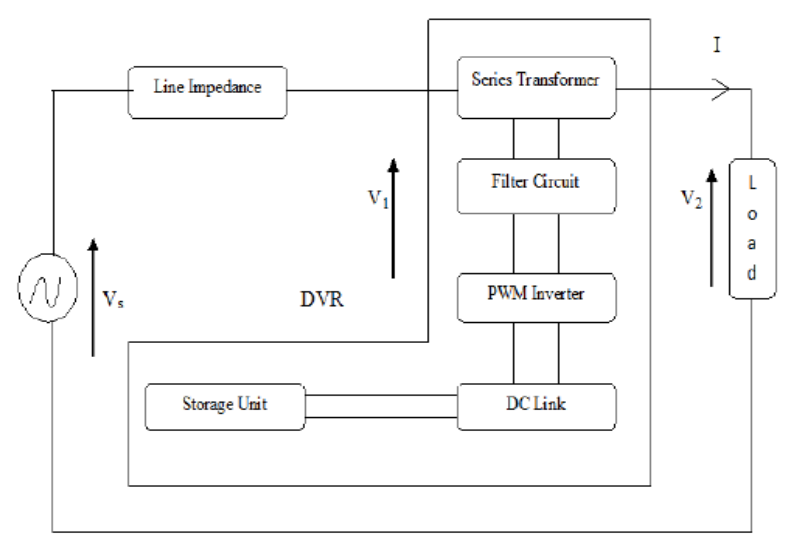

Fig 2 Block diagram of DVR

Here a rectifier is used to store dc voltage in the form of energy, which is utilized by the energy storage circuit. The PWM generator is used to produce/generate compensation voltages. The input to the transformer is always filtered so as to avoid unwanted harmonic components. In this work the voltage reference calculation technique is used to inject the correction voltage. The Synchronous Reference Frame (SRF) method is used to inject the compensation voltage which can be calculated based on the instantaneous values of the supply voltages. At normal operating conditions, the losses in the DVR is minimum and when an event occurs, the DVR will 
react suddenly by the injection of required voltage to the three phase line. The SRF will produce the three phase reference voltage to the input phase.

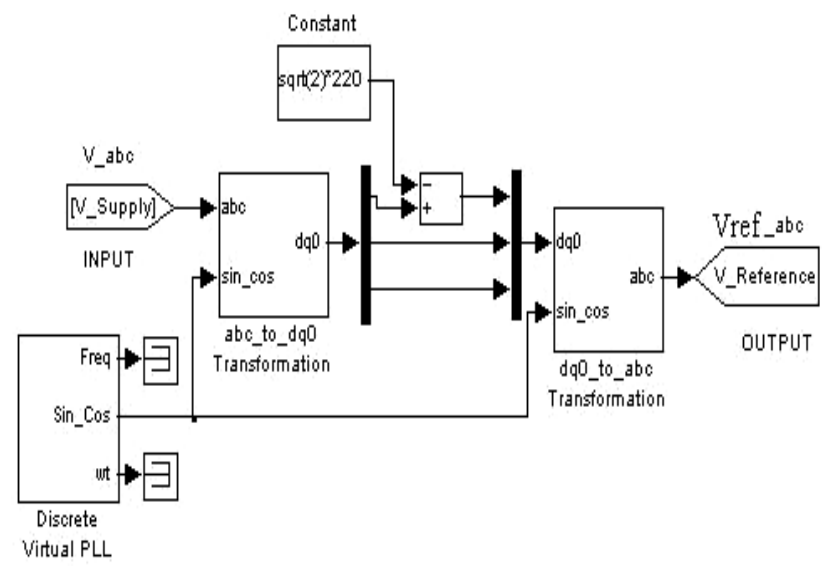

Fig 3 Reference voltage calculation using abc to dq0 transformation

The transformation algorithm used here is abc to dq0 transformation, where dq0 stands for direct-quadrature-zero transformation, which simply rotates the three phase plane to reduce the computational difficulty and is first implemented by Robert H Park. By this control algorithm, we can represent both the source and reference voltage in the dq0 frame. And when the fault occurs, there will be a deviation in the dq0 reference frame, by checking the difference in dq0 components in the frame; the designed control algorithm will generate a voltage signal through the sinusoidal PWM. In normal conditions, the PI controller is used to control the reference voltages, having a considerable disadvantage of slow response to fast varying voltage conditions.

\section{SIMULATION OF VOLTAGE SAG AND SWELL EVENTS}

A test system is simulated with a three phase fault with the duration of $0.25 \mathrm{sec}$ to $0.75 \mathrm{sec}$. The fault is generated with a three phase to ground condition so as to get all three phases get affected. The supply is a $230 \mathrm{~V}, 50 \mathrm{~Hz}$, three phase supply. The fault resistance is applied as $500 \Omega$ for the above given time duration. The simulation model is given in the figure 4 . The three phase RLC load and Y-Y transformer is also used in the test system. The sag generated waveforms are observed in the scope. The swell is created by replacing the three phase source with a programmable one. The swell is generated for the time duration of $0.25 \mathrm{sec}$ to $0.75 \mathrm{sec}$, and the corresponding wave form is observed in the scope

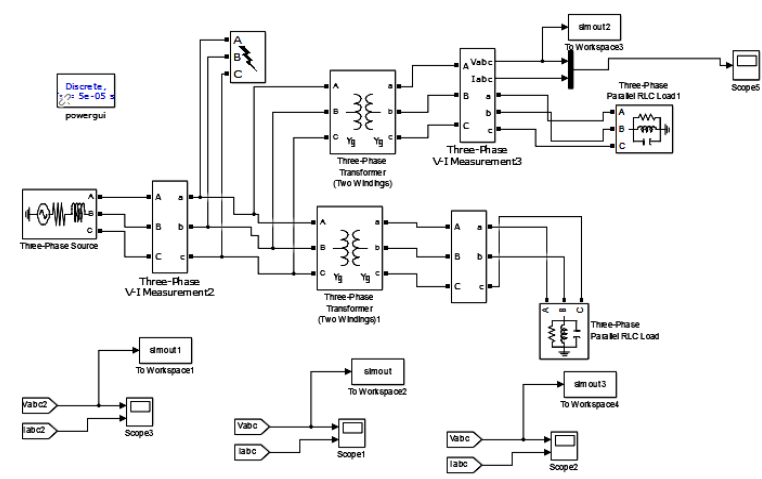

Fig 4 Simulation of sag event

\section{FUZZY BASED DVR}

The fuzzy based DVR is designed as a hybrid system developed so as to overcome the losses caused by the conventional PI controller based design by improving the transient behavior and steady state response. The main advantage of choosing a fuzzy based design is to avoid the complexity of developing a mathematical model. The fuzzy logic mainly deals with the probabilistic approach to minimize lengthy computation works and to implement artificial intelligence resembles like human behavior in real time problem solving. It is observed that the conventional PI controllers are susceptible to the variation in the energy storage system parameters and thereby making the system more complex and sensitive. In the proposed method, Mamdani type fuzzy logic controller is selected for the computation purpose.

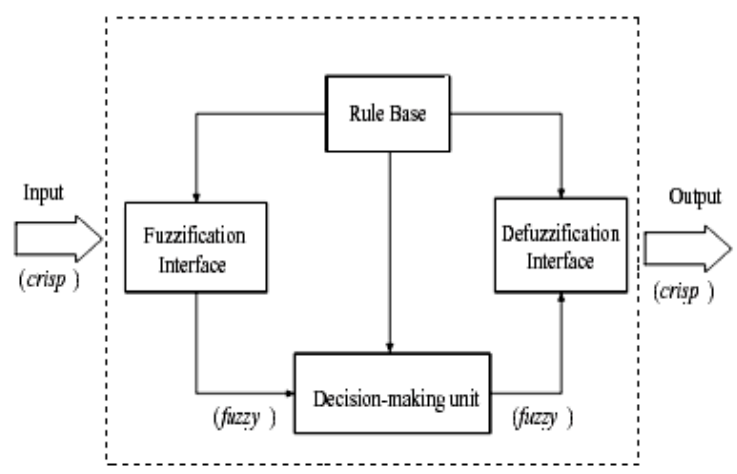

Fig 5 Basic fuzzy logic controller configuration

The main architecture of a fuzzy logic controller is shown in figure 5. Here the computation is based on "degrees of truth" when compared to "true and false" in Boolean algebra. The idea of fuzzy logic was first advanced by Dr. Lotfi Zadeh of the University of California. Fuzzy logic seems closer to the way our brains work. The main parts in the FLC configuration are fuzzification interface, the rule base, the decision making unit and the de-fuzzyification interface. The input to the FLC is of crisp in nature, i.e. taken from the real world. The rule base is formed by the set of linguistic rules related to the particular controller. Here there are two inputs to the fuzzification unit, the error (e) and the change in error $(\Delta \mathrm{e})$ which are fuzzified and can be identified in terms of their membership values, ranging in between 0 and 1 . The inference mechanism is used to collect all the linguistic rules and to convert the input conditions to fuzzified output. The defuzzification unit is used to convert the fuzzy values into crisp values and thereby making them to interact with the real world. Centroid based defuzzification method is used here.

The FLC is designed to control the inverter action based on the designed rule base. There are a total of 49 rules based linguistic variables on the combination of seven membership functions relating the error and change in error. These linguistic variables have different membership levels ranging between 0 and 1 . The crisp output generated by the FLC is used to control the PWM generator circuit. It minimizes the computation time and improves the response of the system under varying conditions. In the unbalanced condition, the FLC will provide the required signals to the PWM. The set of 49 rules developed on the basis of error and change in error is given in table 1 . 
Table 1: Rule base of the designed FLC for error and change in error

\begin{tabular}{|c|c|c|c|c|c|c|c|}
\hline $\mathbf{e}$ & NB & NM & NS & $Z$ & PS & PM & PB \\
\hline NB & NB & NB & NB & NB & NM & NS & $Z$ \\
\hline NS & NB & NB & NB & NM & NS & $Z$ & PS \\
\hline$Z$ & NB & NM & NS & $Z$ & PS & PM & PB \\
\hline PS & NM & NS & $Z$ & PS & PM & PB & PB \\
\hline PM & NS & $Z$ & PS & PM & PB & PB & PB \\
\hline PB & $Z$ & PS & PM & PB & PB & PB & PB \\
\hline
\end{tabular}

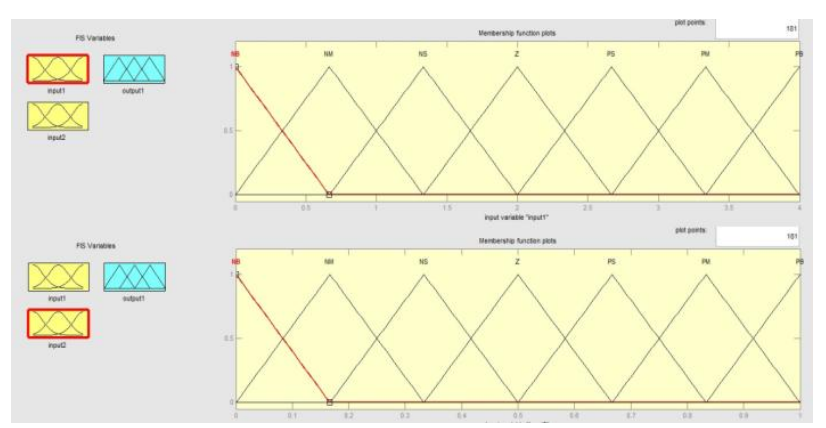

Fig 6 FIS editor for error (e) and change in error $(\Delta e)$

The above FIS editor shows the seven membership functions, say, Negative $\operatorname{Big}(\mathrm{NB})$, Negative Medium (NM), Negative Small(NS),Zero(Z), Positive Small(PS), Positive Medium(PM) and Positive Big(PB). The all available 49 rules are written in FIS. The rules are formed; one example is given as "IF e is $Z$ AND $\Delta \mathrm{E}$ is $\mathrm{Z}$ THEN output is $\mathrm{Z}$ ". The fuzzification unit determines the membership value of each and every fuzzy set.

\section{SIMULATIONS AND RESULTS}

The system is designed to operate at a frequency of $50 \mathrm{~Hz}$. The sag and swell wave forms are observed and the corresponding correction is applied using the DVR plus FUZZY system. The output of ANN controller is the reference variable for the PWM generator

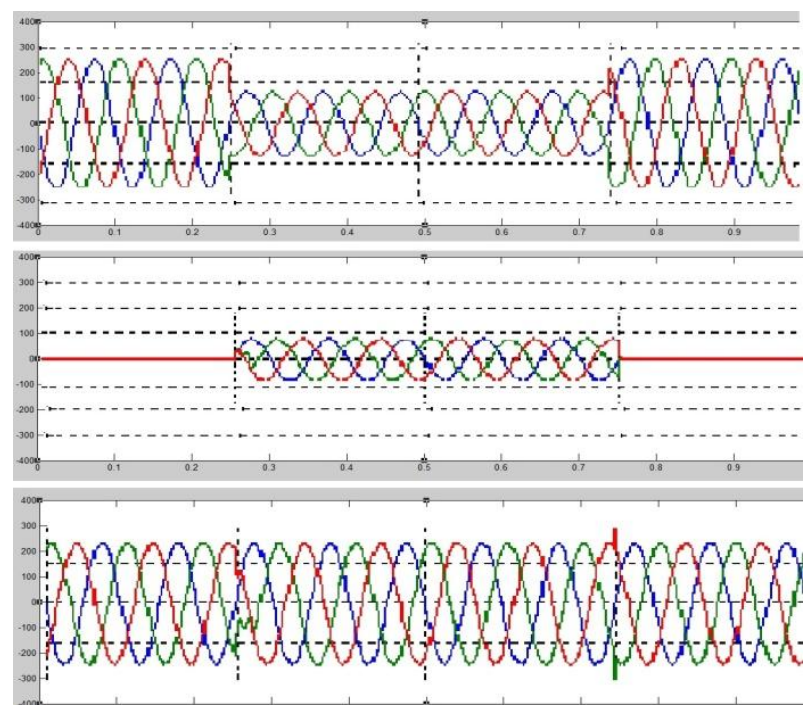

Fig 7 Simulation results for voltage sag; (a) sag occurrence for a $230 \mathrm{~V} / 50 \mathrm{~Hz}$ supply for duration of $0.25-0.75$ seconds, (b) DVR injected voltage, (c) final load output voltage after compensation
The simulations are carried out for voltage sag and swell events. The simulation is executed in the variable step discrete instead of ode 45 because of the lack of continues states. It is observed that the voltage wave form obtained after the compensation made by the DVR and FLC is true and reliable

It is clearly observed the injection voltage level of the DVR's injection transformer. For the test purpose an additional scope is connected. In the future work, this voltage reading can be used in the smart grids. The compensation of neural network based Dynamic voltage restorer and the training performance of the ANN controllers for voltage sag event is shown in figure 7. The Total Harmonic Distortion (THD) is measured by using FFT analysis and is found as $2.01 \%$.

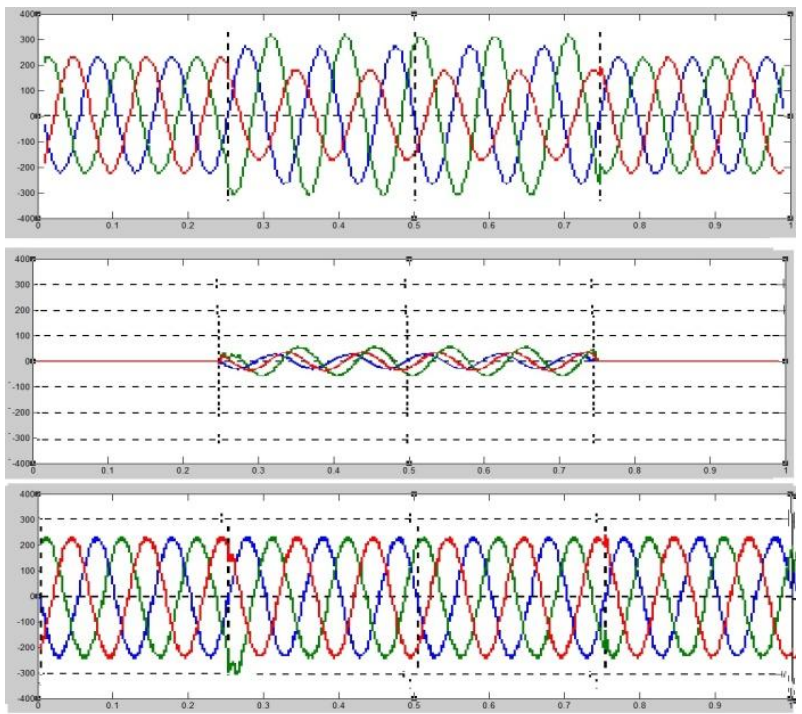

Fig.8 Simulation results for voltage swell; (a) sag occurrence for a $230 \mathrm{~V} / 50 \mathrm{~Hz}$ supply for duration of 0.25 0.75 seconds, (b) DVR injected voltage, (c) final load output voltage after compensation

Fig. 8 shows the voltage swell at $t=0.25$ seconds for a duration of 0.5 seconds; the IDVR injects series voltage with phase angle of $180^{\circ}$ voltage supply and compensates the voltage swell. The neural network controller clearly provides better performance. The compensation voltage is shown in figure 8(b). The Total Harmonic Distortion (THD) is measured by using FFT analysis and is found as $2.09 \%$.

\section{CONCLUSION}

In this research paper, the power quality events like voltage sag and voltage swell are simulated in Matlab. The mathematical models are formed in test environment. The performance of the DVR is evaluated in this paper. DVR has a tremendous application for voltage sag compensation for sensitive loads. The major operation principles of DVR includes, the compensation techniques, the transformer voltage injection methods, PWM inverter, PI based control of PWM etc. are also discussed. Finally a Fuzzy system is developed to increase the reliability of the compensation system. Mamdani type fuzzy logic controller is selected and designed on the required rule base. The above hybrid test system has the capability to compensate for voltage sags at the distribution side. The proposed controller has fast dynamic response, and the THD is lowered when compared to the conventional techniques. The DVR itself is a simple system which consists of low cost, easy design, lesser computational complexity, etc. The designed FLC is capable of dealing with a large number of samples. 


\section{REFERENCES}

[1] Ghosh, A. and Ledwich, G. Power Quality Enhancement using Custom Power Devices. Kluwer Academic Publishers, United States, 2002.

[2] Liu, J. W., Choi,S. S., \& Chen, S. "Design of step dynamic voltage regulator for power quality enhancement," IEEE Transactions on Power Delivery, vol. 18 , no.4, pp. 1403 - 1409, 2002.

[3] D. Mahinda Vilathgamuwa, A.A.D. Ranjith Perera and S. S. Choi, "Voltage sag compensation with energy optimized Dynamic Voltage Restorer", IEEE Transactions Power Delivery, Vol. 18, No. 3, pp. 928936, July 2003.

[4] IEEE Standards Board (1995), "IEEE Std. 1159-1995" IEEE recommended practice for monitoring electric power quality, IEEE Inc. NewYork.

[5] Bollen. M , "Understanding power quality problems: Voltage sags and interruptions," Piscataway, NJ, IEEE Press, 2nd edition 2000

[6] Pirjo Heine and Matti Lehtonon, "Voltage sag distributions caused by power system faults", IEEE Transactions on Power Systems, Vol. 18, No.4, pp. 13671373, November 2003.

[7] Yan Zhang and Jovica V. Milanovic, "Global voltage sag mitigation with FACTS based devices", IEEE Transactions on Power Delivery, Vol. 25, No. 4, pp. 2842-2850, October 2010.

[8] E.A.Mohamed , N.D. Rao, "Artificial Neural Network based fault diagnostic system for electric power distribution feeders," Electric Power System Research, Vol. 35, No. 1, pp. 1-10, 35 October 1995.

[9] B. Bae, J. Jeony, J. Lee and B. Han, "Novel sag detection method for line-interactive Dynamic Voltage Resorer", IEEE Transactions on Power Delivery, Vol. 25, No. 2, pp. 1210-1211, April 2010.
[10] L.D. Zhang, M.H.J. Bollen, Characteristics of voltage dips (sags) in power systems, IEEE Int. Conf. On Harmonics and Quality of Power (ICHQP), October 1998, Athens, Greece

[11] M.H.Haque —Compensation of distribution system voltage sag by DVR and DSTATCOM\| Power Tech Proceedings, 2001 IEEE Porto, Volume: 1, 10-13 Sept.2001 Pages: 5 pp. vol.1.

[12] H.P. Tiwari, Sunil Kumar Gupta ,IDVR Based On Fuel Cell: An Innovative Back-Up System,\|, International Journal of Environmental Science and Development, Vol.1, No.1,April2010,ISSN:2010-02.

[13] Rosli Omar,N.A. Rahim and 3Marizan Sulaiman, "Dynamic Voltage Restorer Application for Power Quality Improvement in Electrical Distribution System: An Overview" Australian Journal of Basic and Applied Sciences, 5(12): 379-396, 2011.

[14] C.S.Lam, M.C.Wong and Y.D.Han, "Voltage swell and overvoltage compensation with undirectional power flow controlled dyanamic voltage restorer," IEEE Trans Power Delivery, vol. 23, no. 4, pp. 2513-2521, Oct-2008.

[15] Chellali BENACHAIBA, Brahim FERDI, "Voltage Quality Improvement Using DVR" Electrical Power Quality and Utilisation, Journal Vol. XIV, No. 1, 2008.

[16] Gosh, A. and G. Ledwich, "Compensation of distribution system voltageusing DVR". IEEE Trans. Power Deliv. 17 , no 46880, 2002

[17] Carl N.M.Ho, Henery and S.H. Chaung, "Fast Dynamic Control Scheme for Capacitor- Supported Dynamic Voltage Restorer: Design Issues, Implementation and Analysis. IEEE, 2007.

[18] Dolores Borras, M. Castilla, Narciso Moreno and J.C.Monatafio,"wavelet and Neural Structure: A new Tool for Diagnostic of Power system Disturbances", IEEE Transaction on Industrial Applications, vol37, No.1, January 2001. pp. 445-463. 